\title{
Sociometry of a Women Handball Team
}

\author{
Wiga Nurlatifa Romadhoni ${ }^{1}$, Nasuka Nasuka ${ }^{2}$, Erwin Nizar Priambodo ${ }^{3}$ \\ \{wiganurlatifa@mail.unnes.ac.id ${ }^{1}$, nasuka@mail.unnes.ac.id ${ }^{2}$, erwinnizara1@mail.unnes.ac.id ${ }^{3}$ \} \\ Universitas Negeri Semarang, Semarang, Indonesia ${ }^{1,2,3}$
}

\begin{abstract}
Sociometry is one of a research method for measurement and assessment of group cohesion and communications between population units. The main purpose of the study is to determine mutual choices, characteristics of the group relationships and interpersonal relationships. In handball, interpersonal relationships is important in building team structures to achieve high goals. The research information base consisted of survey data from 15 athlete from the women handball team. After analyzing these factors, we can see the group leader, group cohesion, and marginalized individuals of the team. By analyzing interpersonal relationships between team members, we can improve group cohesion that can affect team outcomes. The conclusions from applying the sociometry test is the test can help us to define preferences for the team captain or other social problems in the group we want to investigate and whether the group is united or divided.
\end{abstract}

Keywords: sociometry, interpersonal relationships, sports team, group cohesion.

\section{Introduction}

A successful sports team surely has a good communication between the players, strong leaders and good interpersonal relationships between team members. Harmonization of interpersonal relationships can leads to achieve high goals. To find out how good the communication or interpersonal relationships between the players of course in the process we needed a method to find out. Sociometry is one of a research method for measurement and assessment of cohesion of specific social groups and communications between units of the population [1]. Group cohesion is very important in the evolution of performance as a group where we can find positive relationships as friendships, sympathy and cooperation [2].

In the works of Ussorowska 2016, studying intra-group relationships between players can used sociometry test by Moreno as the main method [3]. Sociometry is based on the fact that people make choices in interpersonal relationships. When gathered, they will choose whether to sit or stand, choose who is friends or who is not friendly, who is the central figure or who is rejected (not liked) in the group or who is isolated [4]. By this method we can investigated the subject opinions, thoughts, views, impressions, and we got to know their interpersonal relationships in order to analyze the personality.

The main purpose of the study is to determine mutual choice, characteristics of group relationships and interpersonal relationships between team members in women's handball team. Handball is a sport whose main goal is to score as many goals or scores as possible 
through dribbling, passing and throwing the ball into the goal. Where there are teams that try to score goals while the other team tries to clear the ball and keep the defense [5]. The performance of a game on a handball team is determined by the player's technical ability, tactical ability, player cohesiveness, psychological or social and physical characteristics of the player itself. All of these elements are very important and are quite related in a very complex handball team in it [6].

In handball, interpersonal relationships is important in building team structure to achieve high goals. The survey data consists from 15 athlete is the information base of the research at women handball team at Semarang, Indonesia. This research methodology of structural analysis small group based on sociometry method. We can see the group leader, group cohesion, and marginalized individuals of the women handball team after analyzing these factors. By analyzing interpersonal relationships between player, we can stimulate positive relationships and improve group cohesion that can affect the results of the team. The conclusions from applying sociometry test is the test can help us to define preferences for the team captain or other social problems in the group we want to investigate and whether the group is united or divided. The connection with the game of handball, with knowledge of the factors that influence interpersonal relationships, allows the coach or the members of the handball team to influence them in eliminating unwanted behavior. In addition, thanks to the awareness of forming and monitoring the right attitude in the team, the coach is able to improve a player's interpersonal situation. By doing this, the general atmosphere within the handball team will improve, so that it correlates with the effectiveness of the team's activities in achieving the highest goals.

\section{Material and methods}

The research methodology used in this study is based on existing sociometriy methods and consists of survey data from 15 athletes from the team of women's handball. Our research took place in Semarang, Indonesia with our women handball team between April 2020 and early June 2020 with 15 players aged between 18 and 23 years old, with a handball experience of 2-5 years. Based on the methods and clause specified in the work of Wäsche (2017) [7], Herbison (2018) [8], Timushkin (2018) [9], Sopa (2018) [10] and Dontsov (2018) [11], we developed a sociometric survey to determine the likes of the members of the handball women team.

This survey also includes the following types of questions based on the methods and principles set out in the work of Viktorovna 2019 [12] and Sopa 2018 [13]. 
Table 1. Questions and answers option for sociometry researchs

\begin{tabular}{|c|c|}
\hline Questions & Answers option \\
\hline \multirow{4}{*}{$\begin{array}{l}\text { Which athlete's members do you prefer to } \\
\text { work out and you prefer can lead the team? }\end{array}$} & $1 \ldots \ldots \ldots \ldots \ldots \ldots \ldots \ldots \ldots \ldots(+3)$ \\
\hline & $2 \ldots \ldots \ldots \ldots \ldots \ldots \ldots \ldots \ldots \ldots \ldots \ldots \ldots \ldots \ldots \ldots \ldots \ldots+2)$ \\
\hline & $3 \ldots \ldots \ldots \ldots \ldots \ldots \ldots \ldots \ldots \ldots \ldots \ldots \ldots \ldots+1)$ \\
\hline & $\begin{array}{l}\text { *you can choose } 3 \text { team members, the first } \\
\text { pick is the person you like the most* }\end{array}$ \\
\hline
\end{tabular}

*compiled by the authors

Furthermore as noted in the works of Viktorovna 2019, in this case it is also necessary to create a matrix of respondents' choices for each question and the need to count the number of mutual choices, made and choices received.

it is necessary to construct a matrix of respondents' choices for each question and calculate the amounts of received, made and mutual choices.

Data collected by the sociometry questionnaire is still difficult to analyze and understand if it has not been processed. So that the sociometric data is easily understood, then the data is presented in tabular form (sociometric matrix) and image form (sociogram). After the sociometry questionnaire was filled out, it was then collected and processed to get an overview of the data.

Processing results of sociometric instruments refer to the following steps: $\{a\}$. Prepare a sociometric table containing the name of the voter and the name chosen, $\{b\}$. enter the data obtained from the sociometry questionnaire into the table with the provisions of number 1 for the first choice (1), number 2 for the second choice (2), number 3 for the third choice (3). The tabulation data for the directional vote is calculated as follows: for the first choice (1) a score of three $(+3)$ is given, for the second choice (2) a score of two $(+2)$ is given, and the third option is given a score of one $(+1)$, and $\{c\}$. From the tabulations that are poured in the form of a sociogram using the sociogram application that is useful to see the mutual choice, characteristics of the group relationships and interpersonal relationships between team members.

\section{Results}

The next step on the basis of the data in our study is to built our athlete's response and build a sociometric matrix. In Table. 2 we listed the subjects with a letter in the first column and assign numbers in sequence. 
Table 2. Sociometric matrix

\begin{tabular}{|c|c|c|c|c|c|c|c|c|c|c|c|c|c|c|c|}
\hline \multirow{2}{*}{$\begin{array}{c}\text { Subjects } \\
\text { (voter) }\end{array}$} & \multicolumn{15}{|c|}{ (Selected) } \\
\hline & $\mathrm{A}$ & $\mathrm{B}$ & $\mathrm{C}$ & $\mathrm{D}$ & $\mathrm{E}$ & $\mathrm{F}$ & $\mathrm{G}$ & $\mathrm{H}$ & I & $\mathrm{J}$ & $\mathrm{K}$ & $\mathrm{L}$ & $\mathrm{M}$ & $\mathrm{N}$ & $\mathrm{O}$ \\
\hline No. & 1 & 2 & 3 & 4 & 5 & 6 & 7 & 8 & 9 & 10 & 11 & 12 & 13 & 14 & 15 \\
\hline A. (1) & $X$ & & & 3 & 1 & & & & & & & 2 & & & \\
\hline B. (2) & 1 & $X$ & 3 & & 2 & & & & & & & & & & \\
\hline C. (3) & 2 & & $X$ & 3 & 1 & & & & & & & & & & \\
\hline D. (4) & 1 & & & $X$ & 2 & & & & & & & & & & 3 \\
\hline E. (5) & 2 & & & & $X$ & 3 & & & & & 1 & & & & \\
\hline F. (6) & & & & 3 & & $X$ & & & 1 & & & & & & 2 \\
\hline G. (7) & 2 & & & & 1 & & $X$ & & & 3 & & & & & \\
\hline H. (8) & 3 & & 2 & & 1 & & & $\mathrm{X}$ & & & & & & & \\
\hline I. (9) & 1 & & & 3 & 2 & & & & $\mathrm{X}$ & & & & & & \\
\hline J. (10) & & & 3 & & 1 & & & & & $X$ & 2 & & & & \\
\hline K. (11) & & & & 1 & 2 & & & & & 3 & $X$ & & & & \\
\hline L. (12) & 1 & & & & 2 & & & & & & & $X$ & 3 & & \\
\hline M. (13) & & & 1 & & 2 & & & & 3 & & & & $X$ & & \\
\hline N. (14) & 3 & & & & 1 & & 2 & & & & & & & $X$ & \\
\hline O. (15) & 1 & & & & & & & & & & & 2 & 3 & & $X$ \\
\hline
\end{tabular}

Based on the selection matrix, a selection chart between team players is built for selection for criteria. The links in group or team are quite extensive, as can be seen from Figure. 1. It can be seen that there is an interpersonal relationship between team players, even though there are three isolated athletes $(\mathrm{B}, \mathrm{H}, \mathrm{N})$ because all the three are not selected as training buddy during training and as leaders. As can be seen from Figure 1 this criterion reveals the highest saturation of bonds, because the links in the team are quite extensive. It can be seen that communication links now cover almost all team members, although there are three $(\mathrm{B}, \mathrm{H}, \mathrm{N})$ isolated team members that no one has chosen as training partners or as a leaders of the team. It can be seen in Table 3 that shows the distribution of each popular, moderate and unpopular team players according to the criteria "partners during training and as leaders in teams". 


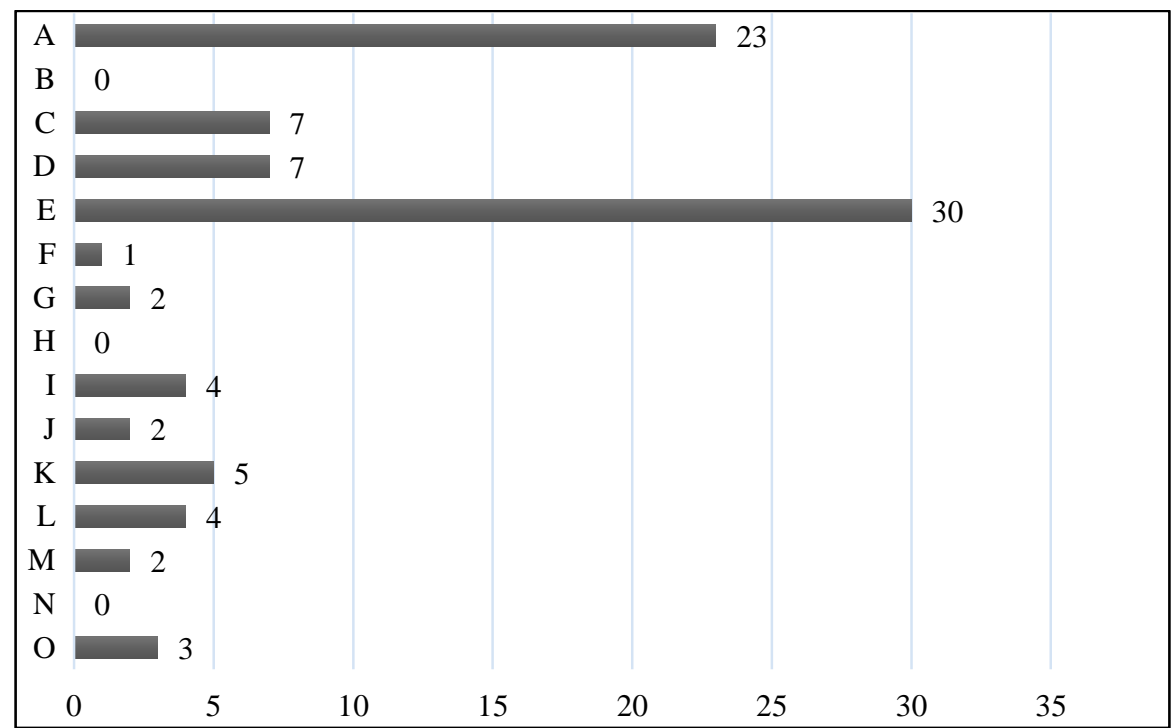

Fig. 1. Team members score selection chart

Table 3. Score \& Index CS (Choice Status)

\begin{tabular}{|c|c|c|c|c|}
\hline No. & Subject Name & SCORE & Nxp & Index CS \\
\hline 1 & $\mathrm{~A}$ & 23 & 45 & 0,511111111 \\
\hline 2 & B & 0 & 45 & 0 \\
\hline 3 & $\mathrm{C}$ & 7 & 45 & 0,155555556 \\
\hline 4 & $\mathrm{D}$ & 7 & 45 & 0,155555556 \\
\hline 5 & $\mathrm{E}$ & 30 & 45 & 0,666666667 \\
\hline 6 & $\mathrm{~F}$ & 1 & 45 & 0,022222222 \\
\hline 7 & $\mathrm{G}$ & 2 & 45 & 0,044444444 \\
\hline 8 & $\mathrm{H}$ & 0 & 45 & 0 \\
\hline 9 & I & 4 & 45 & 0,088888889 \\
\hline 10 & $\mathrm{~J}$ & 2 & 45 & 0,044444444 \\
\hline 11 & $\mathrm{~K}$ & 5 & 45 & 0,111111111 \\
\hline 12 & $\mathrm{~L}$ & 4 & 45 & 0,088888889 \\
\hline 13 & M & 2 & 45 & 0,044444444 \\
\hline 14 & $\mathrm{~N}$ & 0 & 45 & 0 \\
\hline 15 & $\mathrm{O}$ & 3 & 45 & 0,066666667 \\
\hline
\end{tabular}

According to the survey results using matrix of choices, four members of the women's handball team (E, A, C, D) can be distinguished who are most popular to be a partners during workout and as a leaders in the team.

The selection of a sociograms (Figure. 1) enables a comparative analysis of the structures of relationship within the teams and can provide a visuals representation for group leaders and interpersonal relationships of team players who also consider theirs popularity. 


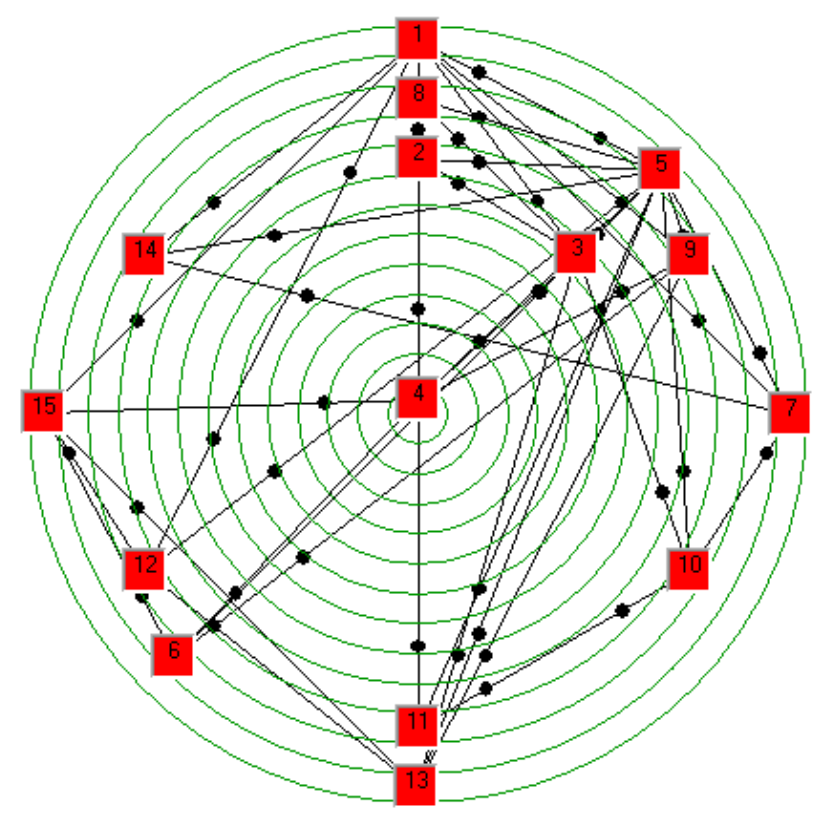

Fig. 2. Sociogram elections

Conducting this sociometry research highlighted the importance of the survey method in scientific research in the field sports team especially in handball. Finding the best partners for sports or workout and the right leader requires communication in its implementation on the process. The group constitutes the basic psychosocial reality of sports activities, its cohesion and capacity depending very much on the performance and satisfaction of the athletes. The commonly known group situations can be characterized as "united", "divided", "confused" or working to acquire a personality [14].

This research can analyze the most popular team member based on the questions, whether the team members prefer to interact in training or workout with several people and choose the right leaders. Some team members are currently falling from the communication structure $(\mathrm{B}, \mathrm{H}, \mathrm{N})$. There are a number of three players from team members who have a total score of zero from the question (namely: $\mathrm{B}, \mathrm{H}, \mathrm{N}$ ), with these results it is possible to expect that there will be developments in the team, so that later the results can be used as evaluations into groups. So, based on that we can conclude that the sociometry in the women handball team is quite favorable. 


\section{Conclusions}

The sociometry test is the test can help us to define preferences for the team captain or other social problem in the group we want to investigate and whether the group is united or divide.

\section{Acknowledgments}

We would like to thank Faculty of Sports Science, Universitas Negeri Semarang, Indonesia for the funding.

\section{References}

[1] Viktorovna VI, Vladimirovna VT, Nikolaevna SN. Sociometry of a volleyball team. J Phys Educ Sport. 2019;19 (2): 1104-11.

[2] Sopa, I.S. \& Pomohaci M. Developing Cohesion in Sportive Group through the Socializing Means of Motor Activities. 2015. Bologna: Medimond Publishing Company by Editografica, p. 135 .

[3] Ussorowska, A., Mieszkowska, M., \& Graczyk, M. Analiza socjometryczna w ocenie grupy społecznej I budowaniu zespołu sportowego= Sociometry in the assessment of social group and sport team building. 2016. Journal of Education, Health and Sport, 6(8): 719-733.

[4] Viktorovna VI, Vladimirovna VT, Nikolaevna SN. Sociometry of a volleyball team. J Phys Educ Sport. 2019;19 (2): 1104-11.

[5] Ziv, G. \& Lidor, R. Physical characteristics, physiological attributes, and on-court performances of handball players: a review. Eur J Sport Sci. 2009. 9(6): 375-86.

[6] Michalsik LB, Madsen K, Aagaard P. Technical match characteristics and influence of body anthropometry on playing performance in male elite team handball. J Strength Cond Res. 2015. 29 (2): 416-28.

[7] Wäsche, H., Dickson, G., Woll, A., \& Brandes, U. (2017). Social network analysis in sport research: an emerging paradigm,European Journal for Sport and Society, 14(2), 138-165.

[8] Herbison, J. D., Vierimaa, M., Côté, J., \& Martin, L. J. (2018), The dynamic nature of connection and its relation to character in youth sport,International Journal of Sport and Exercise Psychology, $1-10$.

[9] Timushkin, A. V., \& Kuzmin, A. M. (2018), Determining the leader in a professional team in the relationship process in a sports team. News of the Saratov University. New series. Philosophy Series. Psychology. Pedagogy, 18 (2).

[10] Sopa, I. S., \& Pomohaci, M. (2018), Discovering the leader of a volleyball team using the sociometric survey method. Timisoara Physical Education \& Rehabilitation Journal, 10(3).

[11] Dontsov, D. A., \& Sagova, Z. A. (2018), Methods of social and psychological diagnostics of sports groups and groups of younger schoolchildren, adolescents and youths,School technology, $1,89-102$.

[12] Viktorovna VI, Vladimirovna VT, Nikolaevna SN. Sociometry of a volleyball team. J Phys Educ Sport. 2019;19 (2): 1104-11.

[13] Sopa, I. S. \& Pomohaci, M. Discovering the leader of a volleyball team using the sociometric survey method. Timisoara Physical Education \& Rehabilitation Journal. 2018. 10(3).

[14] William A. Darity. (2008). International Encyclopedia of the Social Sciences: 2nd Edition. Macmillan Reference USA. 